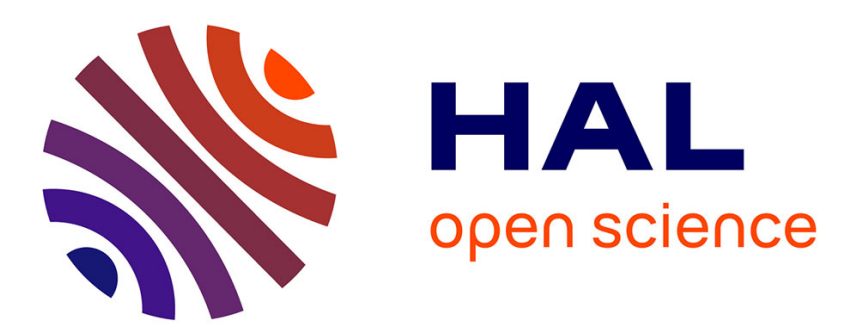

\title{
Mössbauer spectroscopy of the spin glass compounds FexMg1 - xCl2
}

F. Bensamka, D. Bertrand, A.R. Fert, G. Jehanno, J.A. Nasser

\section{To cite this version:}

F. Bensamka, D. Bertrand, A.R. Fert, G. Jehanno, J.A. Nasser. Mössbauer spectroscopy of the spin glass compounds FexMg1 - xCl2. Journal de Physique, 1987, 48 (6), pp.1041-1050. 10.1051/jphys:019870048060104100 . jpa-00210512

\section{HAL Id: jpa-00210512 https://hal.science/jpa-00210512}

Submitted on 1 Jan 1987

HAL is a multi-disciplinary open access archive for the deposit and dissemination of scientific research documents, whether they are published or not. The documents may come from teaching and research institutions in France or abroad, or from public or private research centers.
L'archive ouverte pluridisciplinaire HAL, est destinée au dépôt et à la diffusion de documents scientifiques de niveau recherche, publiés ou non, émanant des établissements d'enseignement et de recherche français ou étrangers, des laboratoires publics ou privés. 
Classification

Physics Abstracts

$75.40-76.80$

\title{
Mössbauer spectroscopy of the spin glass compounds $\mathrm{Fe}_{x} \mathbf{M g}_{1-x} \mathrm{Cl}_{2}$
}

\author{
F. Bensamka $\left({ }^{*}\right)$, D. Bertrand $(*)$, A. R. Fert $\left({ }^{*}\right)$, G. Jehanno $\left({ }^{* *}\right)$ and J. A. Nasser $\left({ }^{* *}\right)$ \\ (*) Laboratoire de Physique des Solides, associé au CNRS, INSA, av. de Rangueil, 31077 Toulouse Cedex, \\ France \\ (**) D.Ph.G./S.R.M., CEN Saclay, 91191 Gif-sur-Yvette Cedex, France
}

(Reçu le 22 juillet 1986, révisé le 9 février, accepté le 13 février 1987)

\begin{abstract}
Résumé. - Nous présentons une étude par spectrométrie Mössbauer du composé dilué de type Ising $\mathrm{Fe}_{x} \mathrm{Mg}_{1-x} \mathrm{Cl}_{2}$ qui présente pour les faibles concentrations $(x<0,5)$ un comportement verre de spin. Les spectres ont été réalisés sur trois monocristaux de concentration $x=0,55,0,45$ et 0,30 . Les résultats montrent que lorsque l'on abaisse la température un rapide élargissement de la raie de droite apparaît à des températures (respectivement $9,5 \mathrm{~K}, 7 \mathrm{~K}$ et $4 \mathrm{~K}$ ) nettement supérieures aux températures du maximum de la susceptibilité continue $(7,5 \mathrm{~K}, 3,70 \mathrm{~K}$ et $1,65 \mathrm{~K})$, en particulier pour les plus faibles concentrations en $\mathrm{Fe}^{2+}$. Les spectres Mössbauer obtenus à basse température peuvent être décomposés en la superposition d'un spectre hyperfin et d'un spectre paramagnétique. L'intensité de la composante paramagnétique diminue progressivement lorsque la température décroît. Une distribution de champ hyperfin ainsi qu'un modèle de relaxation sont testés mais ne peuvent rendre compte de l'asymétrie de la raie de droite aux basses températures. A partir de l'analyse de la séparation quadrupolaire nous proposons une interprétation des résultats en termes d'agrégats : les agrégats observés à $T_{M}$ correspondent à des groupes de spins en position de premiers voisins dans le plan, lorsque la température diminue les spins isolés ou faiblement couplés viennent grossir progressivement les agrégats entraînant une diminution du pourcentage paramagnétique. Ce mécanisme conduit probablement à un comportement collectif d'agrégats en interaction.
\end{abstract}

\begin{abstract}
We report Mössbauer measurements on the Ising-type $\mathrm{Fe}_{x} \mathrm{Mg}_{1-x} \mathrm{Cl}_{2}$ dilute system, which presents a spin-glass behaviour at low concentrations $(x<0.5)$. Experiments have been performed for three different $\mathrm{Fe}^{2+}$ concentrations $x=0.55,0.45$ and 0.30 . Decreasing the temperature, we observe a rapid broadening of the Mössbauer right hand line at $T_{\text {Moss }}=9.5 \mathrm{~K}, 7.5 \mathrm{~K}$ and $4 \mathrm{~K}$ respectively. These temperatures are much higher than the temperatures corresponding to the maxima of the susceptibility curve $(7.5 \mathrm{~K}, 3.7 \mathrm{~K}$ and $1.65 \mathrm{~K}$ respectively), particularly for the lowest two $\mathrm{Fe}^{2+}$ concentrations. Good fits are obtained by the superposition of a paramagnetic quadrupolar spectrum and of a magnetic hyperfine one, the weight of the paramagnetic component decreasing when the temperature decreases. A distribution of hyperfine field and a relaxation model have also been tested but these two models do not explain the asymmetry of the right hand line of the low temperature spectra. Analysing the quadrupolar splitting we propose an interpretation in terms of clusters : the clusters observed at $T_{\text {Moss }}$ correspond to the groups of spins which are nearest neighbours in the cationic plane. When lowering the temperature these clusters grow at the expense of the population of uncoupled spins, a collective behaviour of interacting clusters being probably present at the lowest temperature.
\end{abstract}

\section{Introduction.}

Among the numerous studies dealing with the spin glass systems, much attention has been recently paid to concentrated insulating compounds with short range exchange interactions. Competition between interactions of different signs or topological frustation are invoked to explain the occurrence of the spin glass phase. Mössbauer spectroscopy and neutron scattering experiments are generally used for local magnetic order measurements. Such studies have been recently devoted to the following compounds : $\mathrm{Eu}_{1-x} \mathrm{Sr}_{x} \mathrm{~S}$ (Maletta et al. $[1,2]$ ), EuS $_{x} \mathrm{Se}_{1-x}$ (Bauermann et al. [3]), $\mathrm{Eu}_{1-x} \mathrm{Gd}_{x} \mathrm{~S}$ (Litterst et al. [4]), $\mathrm{ZnCr}_{1.6} \mathrm{Ga}_{0.4} \mathrm{O}_{4}$ (Fiorani et al. 
[5]), $\mathrm{Fe}_{x} \mathrm{Ni}_{78-x} \mathrm{Si}_{9} \mathrm{~B}_{13}$ (Manns et al. [6]) and some aluminosilicate glasses (Ito et al. [7], Sanchez et al. [8]). In the present study, we report Mössbauer measurements carried out on the insulating $\mathrm{Fe}_{x} \mathrm{Mg}_{1-x} \mathrm{Cl}_{2}$ system characterized by a strong uniaxial anisotropy and competing ferro and antiferromagnetic interactions.

In preceding papers (Bertrand et al. $[9,10])$, we reported d.c. susceptibility measurements on the $\mathrm{Fe}_{x} \mathrm{Mg}_{1-x} \mathrm{Cl}_{2}$ system over the whole iron concentration range $(0<x \leqslant 1)$ and we used this data to obtain the magnetic phase diagram. For high iron concentration $(0.55 \leqslant x \leqslant 1)$ the compounds exhibit a behaviour analogous to that of pure $\mathrm{FeCl}_{2}$ : long range antiferromagnetic order appears below a temperature which decreases linearly with decreasing iron concentration. For $x=0.55$ we obtained $T_{\mathrm{N}}=7.5 \mathrm{~K}$ but at lower temperatures a re-entrant spin glass phase was conjectured. For lower iron concentrations $(x<0.5)$ a spin glass-like behaviour is observed with the longitudinal susceptibility exhibiting a typical cusp at $T_{\mathrm{f}}$ and irreversibility phenomena appearing below $T_{\mathrm{f}}\left(T_{\mathrm{f}}=3.70 \mathrm{~K}\right.$ for $x=0.45$ and $T_{\mathrm{f}}=1.65 \mathrm{~K}$ for $x=0.30$ ). Frustration arises from competing intraplane interactions, the nearest neighbour interactions being ferromagnetic and the weaker second neighbour interactions being antiferromagnetic. Recently we showed that no susceptibility cusp is observed in a transverse direction in agreement with the theoretical predictions of Cragg and Sherrington [11], and Roberts and Bray [12] for compounds with large uniaxial crystal fields.

On the same system, Wong et al. have performed specific heat measurements [13] and neutron scattering experiments [14]. Recently [15] they published neutron scattering results on $\mathrm{Fe}_{0.55} \mathrm{Mg}_{0.45} \mathrm{Cl}_{2}$ and discussed the existence of a re-entrant spin-glass phase.

In the present paper we report Mössbauer measurements for three samples with $x$ values 0.55 , 0.45 and 0.30 labelled $A, B$ and $C$ respectively. Mössbauer spectroscopy is a convenient method for investigating short range magnetic order. Furthermore it involves a short experimental time scale $\left(10^{-7}-10^{-8} \mathrm{~s}\right)$ and therefore may provide useful information if dynamical effects are present. Let us recall that in the case of pure $\mathrm{FeCl}_{2}\left(T_{\mathrm{N}}=24 \mathrm{~K}\right)$ the hyperfine field is zero because the Fermi contact term and the orbital contribution almost cancel each other. One might expect that dilution with $\mathrm{Mg}$ modifies this exceptional situation. It appears indeed that the hexagonal lattice parameters of $\mathrm{FeCl}_{2}$ are a little smaller than those of $\mathrm{MgCl}_{2}$ although $\mathrm{Fe}^{2+}$ ions are bigger than $\mathrm{Mg}^{2+}$ ions. This seemed to indicate that dilution with $\mathrm{Mg}$ lowers the partial covalent character of $\mathrm{FeCl}_{2}$ which would modify the relative importance of the two major contributions to the hyperfine field.

\section{Experimental details.}

$\mathrm{FeCl}_{2}$ and $\mathrm{MgCl}_{2}$ having identical crystal structure and very close lattice parameters, single crystals of the solid solution $\mathrm{Fe}_{x} \mathrm{Mg}_{1-x} \mathrm{Cl}_{2}$ can be grown over the entire concentration range. Large single crystals were prepared by the Bridgman method. The proportions of $\mathrm{Fe}^{2+}$ and $\mathrm{Mg}^{2+}$ ions were obtained by atomic absorption spectroscopy and gave values close to the nominal ones (Bertrand et al. [10]). Several different results show that the samples have good homogeneity. Chemical analysis of different parts of the same crystal gave very similar $x$ values. Moreover, we obtained a good reproducibility in our parallel susceptibility measurements for various samples of a given crystal except for the crystal with $x=0.55$ for which a small concentration gradient is probably present. Finally, recent magneto-optical measurements on a thin platelet with $x=0.30$ confirmed the good homogeneity of this sample.

In order to prevent hydratation of the samples, the Mössbauer absorbers were prepared by cleaving inside a glove box filled with dry helium gas and then placed in an air-tight lucite holder. The surface of the disc-shaped absorbers was about $1 \mathrm{~cm}^{2}$. Their thicknesses $(e)$ were estimated by electronic absorption measurement and checked by direct measurement at the end of the experiments. For the three samples $\mathrm{A}, \mathrm{B}$ and $\mathrm{C}$ we found $e=270 \mu \mathrm{m}, e=$ $330 \mu \mathrm{m}$ and $e=200 \mu \mathrm{m}$ respectively. These thicknesses are big enough to introduce saturation effects into the Mössbauer spectra as will be seen later.

Mössbauer spectra were recorded using a conventional spectrometer operating in constant acceleration mode. We used a $25 \mathrm{mCi}$ source of ${ }^{57} \mathrm{Co} / \mathrm{Rh}$ but in the tables the isomer shifts will be given with respect to metallic iron (at room temperature). The $\gamma$ rays were directed along the trigonal axis $(c)$ perpendicular to the crystal plane.

\section{Paramagnetic region.}

At room temperature, each of the samples shows a Mössbauer spectrum consisting of a unique $\mathrm{Fe}^{2+}$ quadrupolar doublet and there is no visible parasitic contribution. The stronger intensity of the high energy line shows that the quadrupole interaction is positive as it is in pure $\mathrm{FeCl}_{2}$ but the area ratio of the two lines $\left(I_{2} / I_{1}\right)$ is much lower than the calculated ratio for a thin absorber $\left(I_{2} / I_{1}=3\right)$. This discrepancy arises from saturation effects due to the important thickness of the absorbers. Indeed, we verified for the case of sample $B$, that a very good fit for the whole spectrum can be obtained by using the transmission integral calculation with an effective thickness $t=10$ as deduced from the measured thickness directly. As this fitting procedure is time consuming it was not generally used and for example all the 
Table I. - Characteristics of resonance lines at various temperatures. I.S : isomer shift with respect to metallic iron at room temperature. $\Delta E_{Q}:$ quadrupolar splitting. $2 \Gamma$ : middle height linewidth. $I_{2} / I_{1}:$ intensity ratio of the right and left hand lines.

\begin{tabular}{|c|c|c|c|c|c|c|c|c|c|c|c|c|c|c|c|c|c|}
\hline \multicolumn{6}{|c|}{$x=0.55$} & \multicolumn{6}{|c|}{$x=0.45$} & \multicolumn{6}{|c|}{$x=0.30$} \\
\hline $\begin{array}{c}T \\
(K)\end{array}$ & $\begin{array}{c}I . S \\
\mathrm{~mm} / \mathrm{s}\end{array}$ & $\begin{array}{c}\Delta E_{Q} \\
\mathrm{~mm} / \mathrm{s}\end{array}$ & $\begin{array}{c}2 \Gamma_{1} \\
\mathrm{~mm} / \mathrm{s}\end{array}$ & $\begin{array}{c}2 \Gamma_{2} \\
\mathrm{~mm} / \mathrm{s}\end{array}$ & $I_{2} / I_{1}$ & $\begin{array}{c}T \\
(\mathrm{~K})\end{array}$ & $\begin{array}{c}I . S \\
\mathrm{~mm} / \mathrm{s}\end{array}$ & $\begin{array}{c}\Delta E_{Q} \\
\mathrm{~mm} / \mathrm{s}\end{array}$ & $\begin{array}{c}2 \Gamma_{1} \\
\mathrm{~mm} / \mathrm{s}\end{array}$ & $\begin{array}{c}2 \Gamma_{2} \\
\mathrm{~mm} / \mathrm{s}\end{array}$ & $I_{2} / I_{1}$ & $\begin{array}{c}T \\
(\mathrm{~K})\end{array}$ & $\begin{array}{c}I . S \\
\mathrm{~mm} / \mathrm{s}\end{array}$ & $\begin{array}{c}\Delta E_{Q} \\
\mathrm{~mm} / \mathrm{s}\end{array}$ & $\begin{array}{c}2 \Gamma_{1} \\
\mathrm{~mm} / \mathrm{s}\end{array}$ & $\begin{array}{c}2 \Gamma_{2} \\
\mathrm{~mm} / \mathrm{s}\end{array}$ & $I_{2} / I_{1}$ \\
\hline 295 & 1.095 & 0.722 & 0.27 & 0.27 & 2.46 & 295 & 1.096 & 0.711 & 0.31 & 0.28 & 1.99 & 295 & 1.102 & 0.693 & 0.24 & 0.23 & 2.59 \\
\hline 240 & 1.129 & 0.781 & 0.25 & 0.25 & 2.30 & 247 & 1.129 & 0.769 & 0.31 & 0.28 & 1.89 & 124 & 1.135 & 0.752 & 0.28 & 0.27 & 2.61 \\
\hline 200 & 1.157 & 0.831 & 0.25 & 0.26 & 2.27 & 210 & 1.155 & 0.811 & 0.33 & 0.30 & 1.87 & 190 & 1.166 & 0.821 & 0.34 & 0.34 & 2.59 \\
\hline 170 & 1.179 & 0.859 & 0.25 & 0.26 & 2.18 & 180 & 1.196 & 0.866 & 0.30 & 0.30 & 1.83 & 150 & 1.191 & 0.860 & 0.37 & 0.39 & 2.56 \\
\hline 120 & 1.209 & 0.895 & 0.25 & 0.28 & 2.14 & 120 & 1.213 & 0.885 & 0.30 & 0.33 & 1.87 & 120 & 1.209 & 0.871 & 0.37 & 0.38 & 2.59 \\
\hline 77 & 1.229 & 0.910 & 0.29 & 0.32 & 2.12 & 77 & 1.230 & 0.894 & 0.34 & 0.37 & 1.75 & 77 & 1.235 & 0.873 & 0.27 & 0.27 & 2.38 \\
\hline 50 & 1.240 & 0.911 & 0.29 & 0.32 & 2.05 & 60 & 1.241 & 0.895 & 0.30 & 0.35 & 1.77 & 50 & 1.242 & 0.879 & 0.36 & 0.38 & 2.52 \\
\hline 30 & 1.242 & 0.933 & 0.26 & 0.30 & 2.02 & 32 & 1.246 & 0.918 & 0.31 & 0.36 & 1.79 & 20 & 1.246 & 0.918 & 0.37 & 0.37 & 2.39 \\
\hline 20 & 1.242 & 0.965 & 0.26 & 0.30 & 2.00 & 20 & 1.246 & 0.953 & 0.31 & 0.36 & 1.76 & 10 & 1.247 & 0.975 & 0.32 & 0.33 & 2.26 \\
\hline 10 & 1.243 & 1.066 & 0.26 & 0.31 & 2.07 & 10 & 1.246 & 1.035 & 0.31 & 0.37 & 1.78 & 8 & 1.248 & 1.012 & 0.28 & 0.30 & 2.35 \\
\hline 9 & 1.243 & 1.083 & 0.27 & 0.33 & 2.14 & 8 & 1.247 & 1.061 & 0.30 & 0.39 & 1.92 & 6 & 1.248 & 1.054 & 0.35 & 0.37 & 2.39 \\
\hline 8 & 1.243 & 1.102 & 0.27 & 0.43 & 2.68 & 7 & 1.245 & 1.078 & 0.30 & 0.41 & 2.05 & 4.2 & 1.245 & 1.067 & 0.29 & 0.38 & 2.55 \\
\hline \multirow[t]{2}{*}{7} & 1.240 & 1.127 & 0.28 & 0.63 & 3.55 & 6 & 1.245 & 1.094 & 0.31 & 0.51 & 2.52 & 3.5 & 1.241 & 1.097 & 0.46 & 0.67 & 3.12 \\
\hline & & & & & & 5 & 1.240 & 1.111 & 0.30 & 0.71 & 3.57 & 3.0 & 1.242 & 1.107 & 0.41 & 0.83 & 3.44 \\
\hline
\end{tabular}

quadrupolar spectra were fitted by simply using two independent Lorentzian lines. The deduced isomer shift and quadrupole splitting values are listed in table I together with the linewidths and the intensity ratios.

3.1 ISOMER SHIFT. - The isomer shift shows the same temperature dependence for the three samples. The thermal variation is well accounted for by the second order Doppler effect yielding a characteristic Debye temperature $\theta_{\mathrm{D}}=280 \mathrm{~K}$.

Including the results previously obtained by Nasser and Varret [16] for pure $\mathrm{FeCl}_{2}$, our measurements show that there is a weak linear decrease of the isomer shift with increasing $\mathrm{Fe}^{2+}$ concentration (Fig. 1). This behaviour may be attributed to an increase of the partial covalent character of the compound with increasing $x$ and can also be connected with the variation of the cell volume with iron concentration as mentioned above.

3.2 QUADRUPOLE SPLITTING. - Figure 2 shows the temperature dependence of the quadrupole splitting $\left(\Delta E_{Q}\right)$ for samples $\mathrm{A}$ and $\mathrm{C}$. These results as well as those obtained for sample $B$ are very similar to those observed by Ono et al. for pure $\mathrm{FeCl}_{2}$. Taking into account both the Ono et al. [17] and the Nasser and Varret [16] measurements for pure $\mathrm{FeCl}_{2}$ at $T=295 \mathrm{~K}$ and $T=77 \mathrm{~K}$, we find that the quadrupolar splitting linearly increases with increasing $x$, as shown in figure 3 . In a next paper, both the temperature and the iron concentration dependence of $\Delta E_{Q}$ will be discussed in detail.

\section{Magnetic ordering.}

4.1 EXPERIMENTAL RESUlTS. - Contrary to the case of pure $\mathrm{FeCl}_{2}$ for each of the three samples a measurable hyperfine field is present at low temperatures. The onset of a local magnetic order shows up by a gradual broadening and then by a splitting of the right hand line corresponding to the $\pm \frac{1}{2} \rightarrow \pm \frac{3}{2}$ transitions. The temperature dependence of the

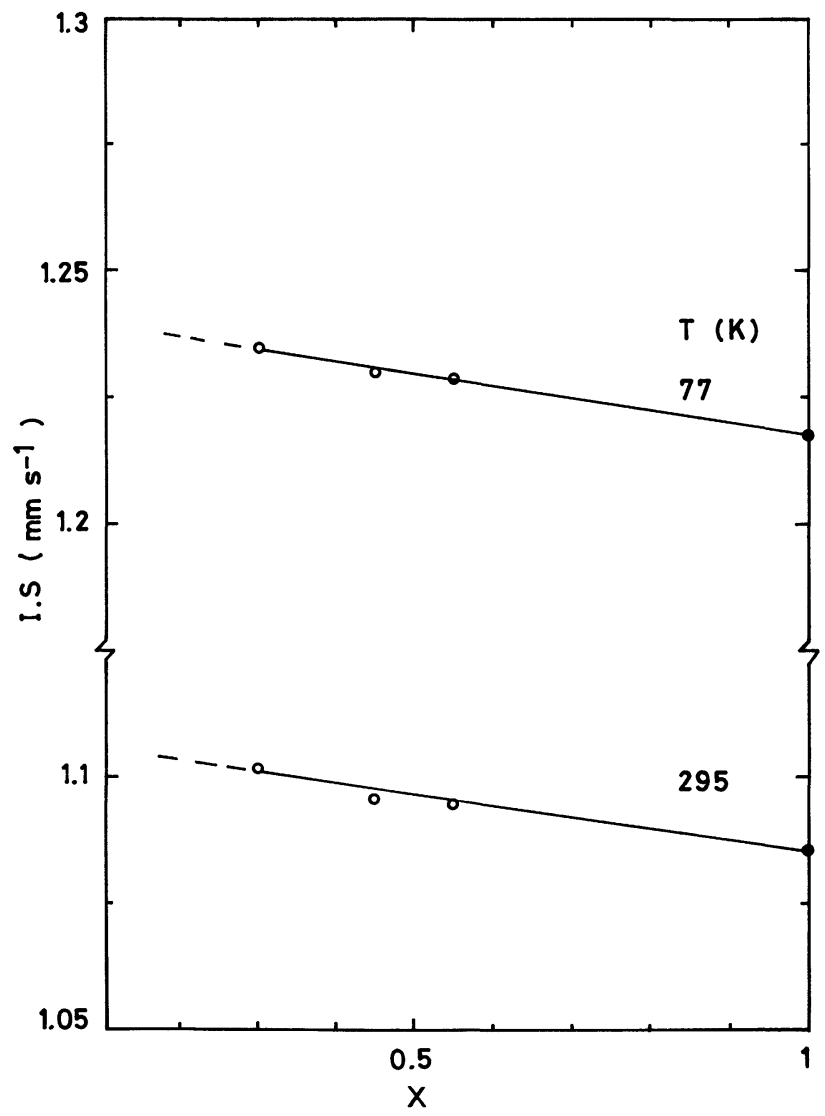

Fig. 1. - Isomer shift versus iron concentration for $T=295 \mathrm{~K}$ and $T=77 \mathrm{~K}$. $\bullet$ Nasser and Varret [16] ; O Our measurements. Full lines are only guides for the eye. 


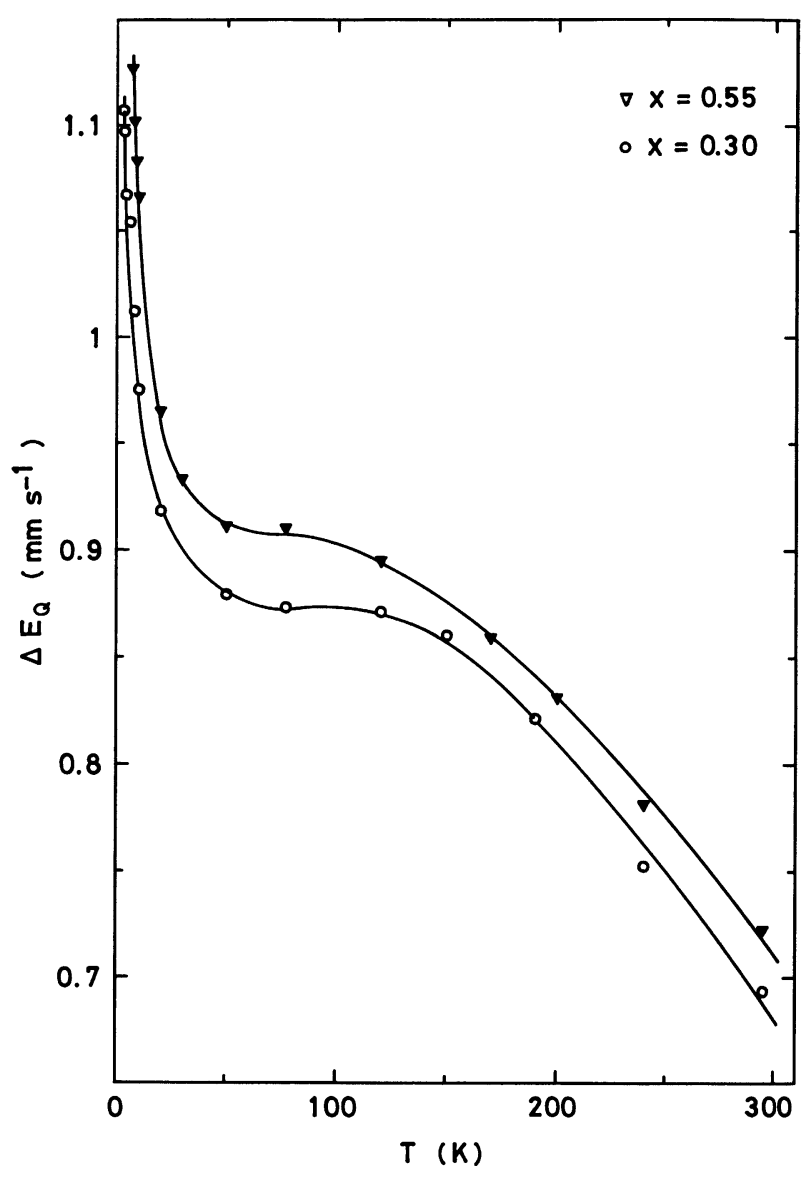

Fig. 2. - Temperature dependence of the quadrupolar splitting $\Delta E_{Q}$ for sample $A(x=0.55) \nabla$ and $\mathrm{C}(x=0.30)$ $O$. Full lines are only guides for the eye.

width of this line is shown in figure 4. Assuming that the temperature where the linewidth suddenly increases corresponds to the onset of local magnetic order, we obtain $T_{\text {Moss }}=9.5 \mathrm{~K}, 7 \mathrm{~K}$ and $4 \mathrm{~K}$ for samples A, B and C respectively. These temperatures are systematically higher than the temperatures corresponding to the susceptibility maximum (considered for simplicity as the freezing temperature for $B$ and $C$ ) which are $7.50 \mathrm{~K}, 3.70 \mathrm{~K}$ and $1.65 \mathrm{~K}$ respectively. In particular for samples corresponding to $x=0.45$ and 0.30 which present a spin glass state at low temperature, this Mössbauer temperature $T_{\text {Moss }}$ is roughly twice as high as the freezing temperature $T_{\mathrm{f}}$.

\subsection{ANALYSIS OF THE SPECTRA.}

4.2.1 Superposition of two subspectra. - At $T<T_{\text {Möss }}$ we observe that a good fit cannot be obtained using only one value for the hyperfine field. We must consider that we have a superposition of at least two spectra: one magnetic hyperfine spectrum and one paramagnetic quadrupolar spectrum. A similar analysis has already been proposed by Maletta and Crecelius [1] for diluted $\mathrm{Eu}_{1-x} \mathrm{Sr}_{x} \mathrm{~S}$ compounds. With decreasing temperature, we ob-

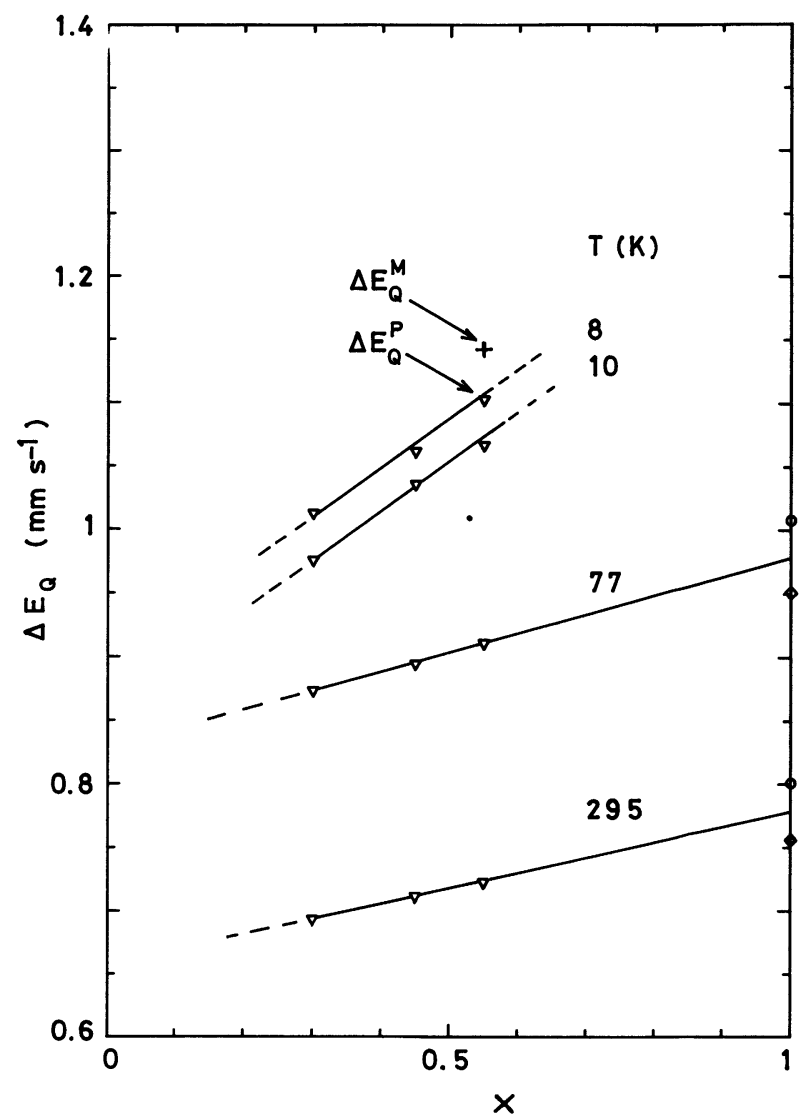

Fig. 3. - Quadrupolar splitting $\Delta E_{Q}$ versus iron concentration at $T=295 \mathrm{~K}, 77 \mathrm{~K}, 10 \mathrm{~K}$ and $8 \mathrm{~K}$. O Ono et al. [17], $\diamond$ Nasser and Varret [16], $\nabla$ Our measurements, + indicates the quadrupolar splitting value for the magnetic component $\Delta E_{Q}^{M}$ at $T=8 \mathrm{~K}$ (see discussion).

serve that the intensity of the paramagnetic component progressively decreases. At the lowest temperature studied $(1.4 \mathrm{~K})$, the percentage of the paramagnetic spectrum only amounts to about $10 \%$ of the total. We examined whether the hyperfine field deviates with respect to the $c$ axis. Such a deviation would modify the lineshape and specially the lefthand line profile by introducing $\Delta m_{\mathrm{I}}=0$ transitions. After comparing the data to theoretical spectra obtained assuming various deviation angles, we concluded the upper limit to be $\theta=10$ degrees. Therefore the spectra were fitted assuming a zero value for $\theta$. This is in agreement with our recent susceptibility measurements showing that no susceptibility cusp is observed in a transverse magnetic field. This assumption is also supported by a recent neutron study [15] (Wong et al.) which showed that there is no observable scattering from a transverse spin component.

Because the effective thickness of the absorber is high, a complete analysis of each whole spectrum would require the use of the transmission integral approach. We adopted the simpler procedure of obtaining the hyperfine parameters only from the right hand part of the total spectrum. This part 


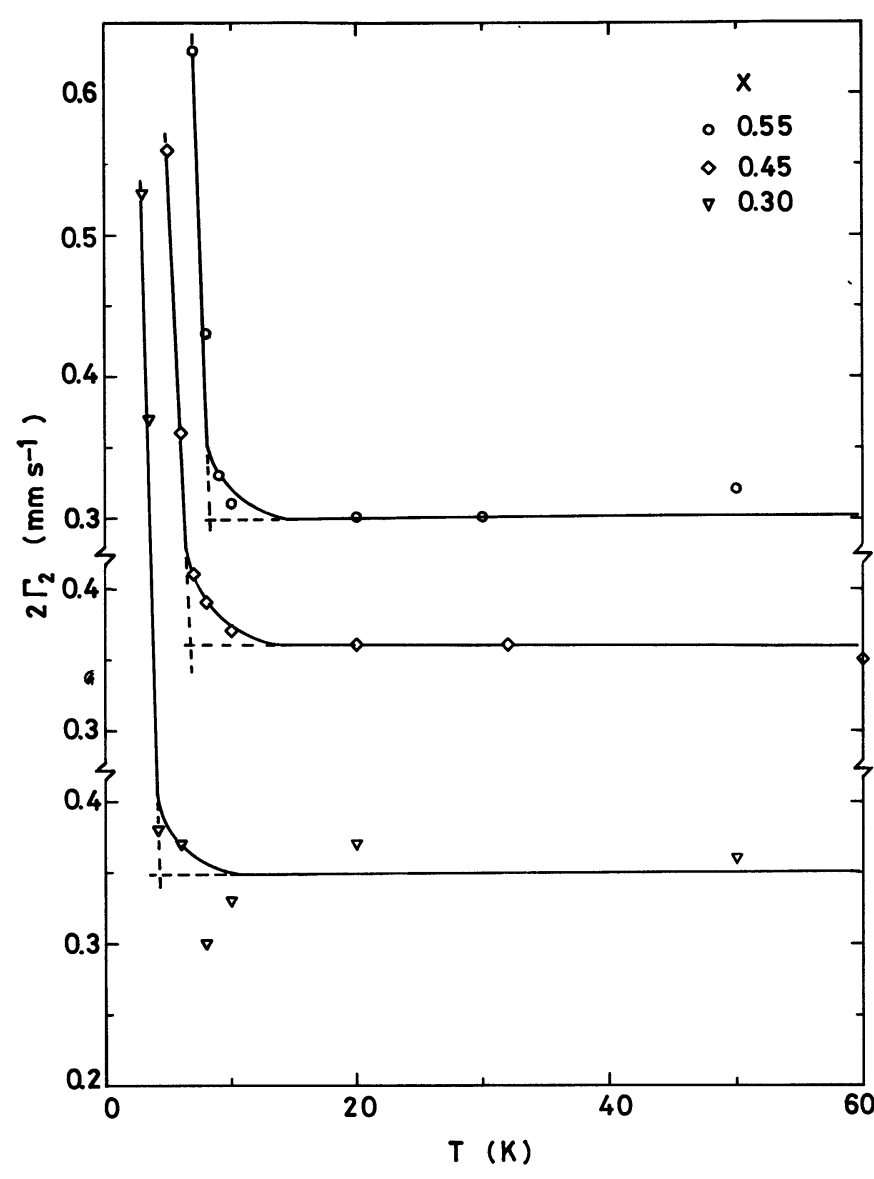

Fig. 4. - Temperature dependence of full width at half height for right hand line.

contains enough information to provide reliable results for the magnitude of the hyperfine field (assumed unique) and for the quadrupole interactions, once the common isomer shift has been previously established near $T_{\text {Möss }}$ (Table I). Only approximate results can be obtained for the relative proportions of the magnetic and non-magnetic components when no account is taken of the high effective thickness of the absorbers. Good fits to the right-hand part of the spectrum are generally obtained as can be seen in figures $5 \mathrm{a}, 5 \mathrm{~b}$ and $5 \mathrm{c}$ for the three samples. The parameters obtained from these fits are listed in table II. The hyperfine fields measured at various temperatures are indicated in figure 6 for the three samples. Plotting the reduced hyperfine field $H_{\mathrm{hf}}(T) / H_{\mathrm{hf}}(0)$ as a function of reduced temperature $T / T_{\text {Möss }}\left(H_{\mathrm{hf}}(0)\right.$ is an extrapolated value at $T=0$ ), we observe the same behaviour for the three samples. This behaviour is not far from that of a Brillouin function.

The hyperfine field at zero temperature $H_{\mathrm{hf}}(0)$ linearly decreases as a function of the iron concentration, the extrapolated value for $x=1$ being quite small $(\simeq 5 \mathrm{kOe})$ in agreement with the estimate value for pure $\mathrm{FeCl}_{2}$, the Fermi contact term $H_{\mathrm{c}}$ and the orbital contribution $H_{\mathrm{ORB}}$ have nearly the same size but opposite signs ( $H_{c}$ is negative). In the case of $\mathrm{Fe}_{x} \mathrm{Mg}_{1-x} \mathrm{Cl}_{2}$, a Mössbauer study, in presence of a magnetic field [19] (Jehanno et al.) showed that the hyperfine field is negative.

When analysing each spectrum in terms of two subspectra we observe (Table II) that the quadrupolar splitting of the paramagnetic component $\Delta E_{Q}^{\mathrm{P}}$, when it is present in relatively high amounts (the accuracy is then high), is a little bit smaller than that corresponding to the magnetic subspectrum $\Delta E_{Q}^{\mathrm{M}}$. These different $\Delta E_{Q}$ values, which produce an asymmetrical shape for the right-hand part of the spectrum, cannot be due to sample inhomogeneities. The various tests which were carried out to detect some deviation from an ideal solid solution gave negative results.

We also verified that the observed difference between $\Delta E_{Q}^{\mathrm{M}}$ and $\Delta E_{Q}^{\mathrm{P}}$ could not be due to an incorrect estimate of the $\theta$ value which was blocked to zero to fit the magnetic component. We could not obtain satisfactory fits using a unique adjustable $\Delta E_{Q}$ value for the two subspectra and a non-zero $\theta$ value.

The comparison of the observed $\Delta E_{Q}^{\mathrm{M}}$ and $\Delta E_{Q}^{\mathrm{P}}$ values with the quadrupolar splitting observed above

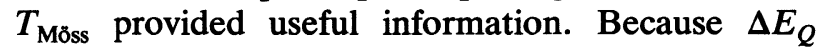
steeply increases with temperature in the vicinity of

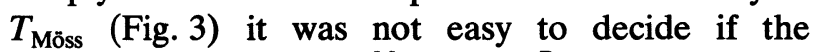
difference between $\Delta E_{Q}^{\mathrm{M}}$ and $\Delta E_{Q}^{\mathrm{P}}$ corresponds to some contribution due to magnetic ordering. More instructive is the $\Delta E_{Q}$ variation with iron concentration (Fig. 4). For $T>T_{\text {Mo̊ss }}, \Delta E_{Q}$ linearly increases with $x$. Now, if we consider the measured $\Delta E_{Q}$ values at $T=8 \mathrm{~K}$, this temperature being higher than $T_{\text {Möss }}(\mathrm{B})$ and $T_{\text {Möss }}(\mathrm{C})$ but lower than $T_{\text {Möss }}(\mathrm{A})$, we observe that the $\Delta E_{Q}^{\mathrm{P}}$ value for sample A is quite consistent with the $\Delta E_{Q}$ values measured for the other two samples, when $\Delta E_{Q}^{\mathrm{M}}$ is clearly higher. These results may be understood if we consider that $\Delta E_{Q}^{\mathrm{M}}$ corresponds to spins belonging to clusters of first neighbour spins. For these clusters, characterized by strong ferromagnetic exchange interactions, the higher $\Delta E_{Q}^{\mathrm{M}}$ is explained by a small electric field gradient induced by molecular field as demonstrated by Ono et al. [17] in the case of pure $\mathrm{FeCl}_{2}$. The smaller $\Delta E_{Q}^{\mathrm{P}}$ value corresponds to isolated spins or weakly interacting moments.

Let us note that in this fitting procedure using two subspectra, we implicitly assumed that the isolated spins experience a rapid electronic relaxation and that the clusters of spins are static at the Mössbauer time scale.

4.2.2 Hyperfine field distribution. - The comparison of table II with table I points out that the linewidths $(2 \Gamma)$ at $T<T_{\text {Möss }}$ are higher than those at $T>T_{\text {Möss. }}$ This broadening could be an indication that a distribution of hyperfine fields is present 


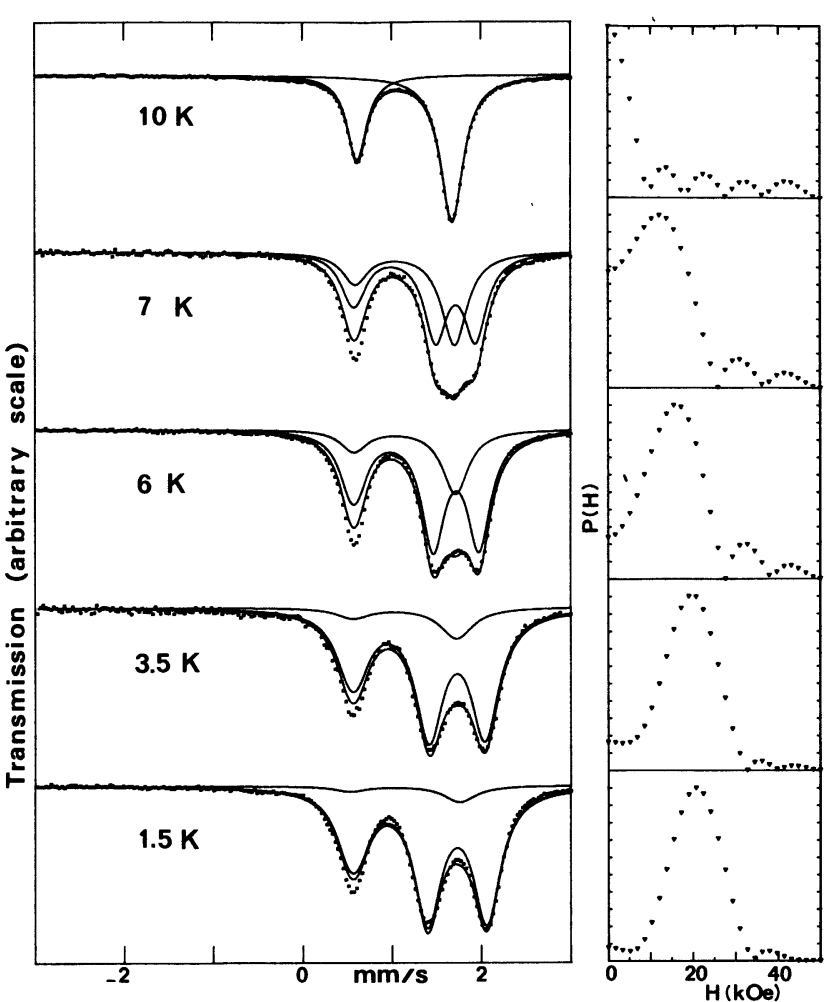

a

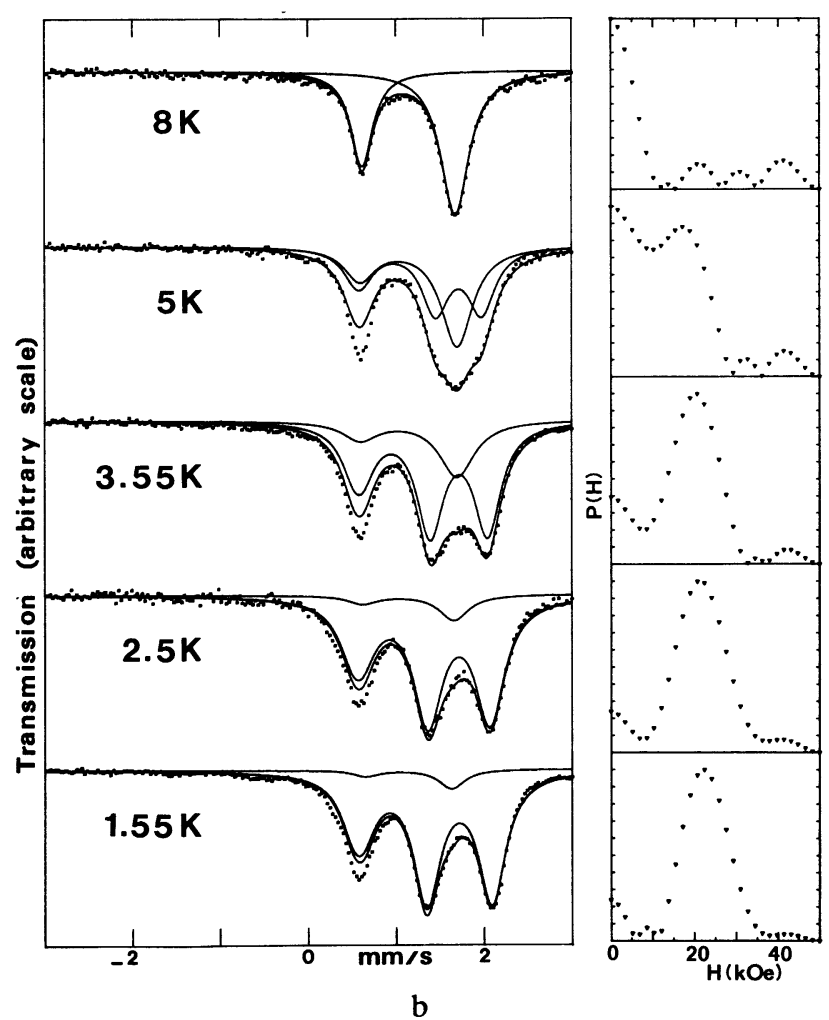

Fig. 5. - Thermal evolution of the spectra below

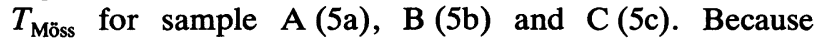
saturation effects are present only the right hand part of the spectra are fitted. Two subspectra were assumed to be present (see text). Second fitting procedure in terms of a hyperfine field distribution $P(H)$ gave the $P(H)$ curves shown on the right of the corresponding spectra.

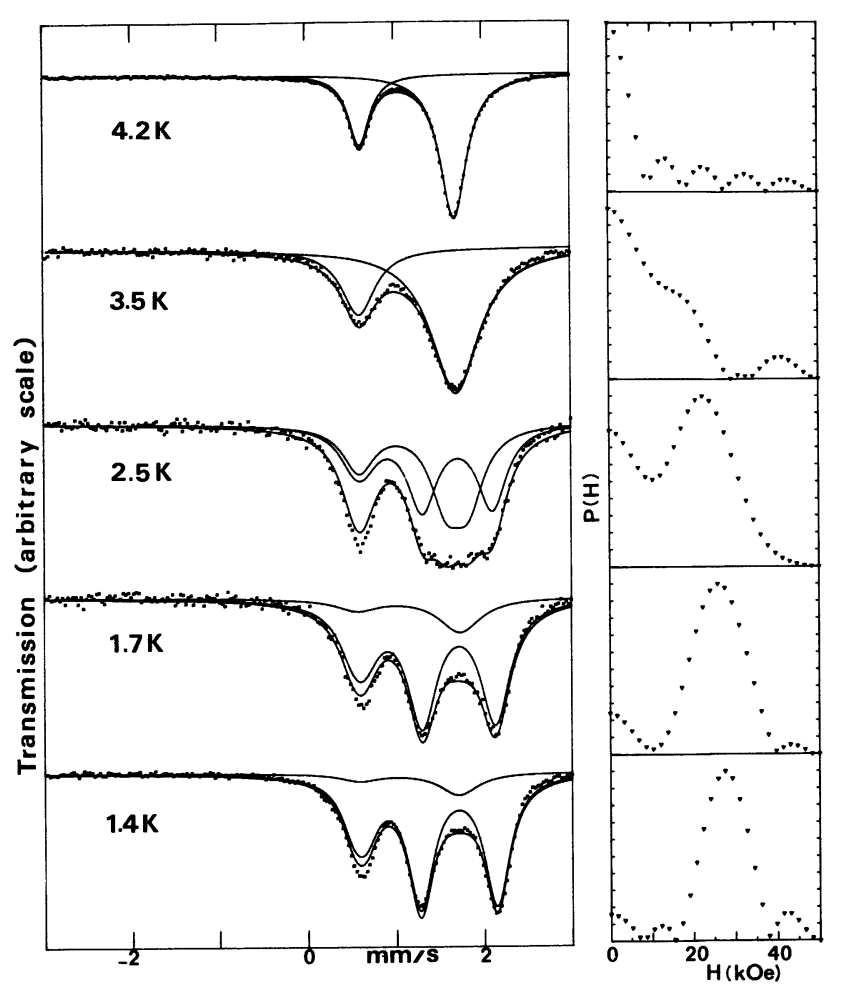

c

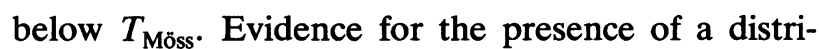
bution is also found from the linewidths near $1.5 \mathrm{~K}$ where, neglecting the weak paramagnetic component and fitting each part of the whole spectrum with a doublet (the ratio of the splittings of the two doublets being blocked at the theoretical value), we find that the linewidths of the right-hand doublet are clearly broader than those of the left-hand doublet and we verified that these different linewidth values cannot be entirely explained by taking the saturation effect into account.

Consequently all the spectra recorded below $T_{\text {Möss }}$ were fitted again using an hyperfine field distribution whose envelope was obtained using the Fourier coefficient method. The isomer shift was still blocked at the value obtained previously and for the intrinsic linewidth we adopted the $2 \Gamma_{2}$ value obtained just above $T_{\text {Möss. }}$ The quadrupolar interaction was assumed to take only one value. The use of only five Fourier coefficients was sufficient to obtain satisfactory fits except in the case of spectra showing a strongly asymmetrical right-hand part. In such a case it would have been necessary to introduce at least two quadrupolar interactions. This has not been done.

The field distributions are given in the right part of figures $5 \mathrm{a}, 5 \mathrm{~b}$ and $5 \mathrm{c}$. For samples $\mathrm{B}$ and $\mathrm{C}$, they clearly exhibit two maxima, the first one corresponding to a zero value of $H_{\mathrm{hf}}$, the second one being situated at a value close to that obtained using the simple superposition of two subspectra (Table II). One can also see that the population corresponding 
Table II. - Characteristics of resonance lines at various temperatures. I.S : isomer shift with respect to metallic iron at room temperature. $\Delta E_{Q}:$ quadrupolar splitting. $2 \Gamma$ : middle height linewidth. $H_{\mathrm{hf}}$ : hyperfine field. $I \%$ : absorption percentage for the magnetic and paramagnetic components.

\begin{tabular}{|c|c|c|c|c|c|c|c|c|c|c|c|c|c|c|c|c|c|}
\hline \multicolumn{6}{|c|}{$x=0.55$} & \multicolumn{6}{|c|}{$x=0.45$} & \multicolumn{6}{|c|}{$x=0.30$} \\
\hline$\underset{(\mathrm{K})}{T-}$ & $\begin{array}{c}I . S \\
\mathrm{~mm} / \mathrm{s}\end{array}$ & $\begin{array}{c}2 \Gamma \\
\mathrm{mm} / \mathrm{s}\end{array}$ & $\begin{array}{c}\Delta E_{Q} \\
\mathrm{~mm} / \mathrm{s}\end{array}$ & $\begin{array}{l}H_{\mathrm{hf}} \\
\mathrm{kOe}\end{array}$ & $\begin{array}{c}I \\
(\%)\end{array}$ & $\begin{array}{c}T \\
(\mathrm{~K})\end{array}$ & $\begin{array}{c}I . S \\
\mathrm{~mm} / \mathrm{s}\end{array}$ & $\begin{array}{c}2 \Gamma \\
\mathrm{mm} / \mathrm{s}\end{array}$ & $\begin{array}{c}\Delta E_{Q} \\
\mathrm{~mm} / \mathrm{s}\end{array}$ & $\begin{array}{l}H_{\mathrm{hf}} \\
\mathrm{kOe}\end{array}$ & $\begin{array}{c}I \\
(\%)\end{array}$ & $\begin{array}{c}T \\
(\mathrm{~K})\end{array}$ & $\begin{array}{c}I . S \\
\mathrm{~mm} / \mathrm{s}\end{array}$ & $\begin{array}{c}2 \Gamma \\
\mathrm{mm} / \mathrm{s}\end{array}$ & $\begin{array}{r}\Delta E_{Q} \\
\mathrm{~mm} / \mathrm{s}\end{array}$ & $\begin{array}{l}H_{\mathrm{hf}} \\
\mathrm{kOe}\end{array}$ & $\begin{array}{c}I \\
(\%)\end{array}$ \\
\hline 8 & $\begin{array}{l}1.243 \\
1.243\end{array}$ & $\begin{array}{l}0.33 \\
0.34\end{array}$ & $\begin{array}{l}1.141 \\
1.097\end{array}$ & $\begin{array}{c}10.8 \\
0\end{array}$ & $\begin{array}{l}36 \\
64\end{array}$ & 5 & $\begin{array}{l}1.244 \\
1.244\end{array}$ & $\begin{array}{l}0.37 \\
0.43\end{array}$ & $\begin{array}{l}1.138 \\
1.107\end{array}$ & $\begin{array}{c}16.3 \\
0\end{array}$ & $\begin{array}{l}52 \\
48\end{array}$ & 3.5 & $\begin{array}{l}1.251 \\
1.251\end{array}$ & $\begin{array}{l}0.49 \\
0.47\end{array}$ & $\begin{array}{l}1.100 \\
1.076\end{array}$ & $\begin{array}{c}14.6 \\
0\end{array}$ & $\begin{array}{l}48 \\
52\end{array}$ \\
\hline 7 & $\begin{array}{l}1.243 \\
1.243\end{array}$ & $\begin{array}{l}0.31 \\
0.35\end{array}$ & $\begin{array}{l}1.142 \\
1.118\end{array}$ & $\begin{array}{c}13.9 \\
0\end{array}$ & $\begin{array}{l}61 \\
39\end{array}$ & 4.2 & $\begin{array}{l}1.244 \\
1.244\end{array}$ & $\begin{array}{l}0.35 \\
0.47\end{array}$ & $\begin{array}{l}1.141 \\
1.103\end{array}$ & $\begin{array}{c}18.8 \\
0\end{array}$ & $\begin{array}{l}62 \\
38\end{array}$ & 3.0 & $\begin{array}{l}1.248 \\
1.248\end{array}$ & $\begin{array}{l}0.46 \\
0.53\end{array}$ & $\begin{array}{l}1.132 \\
1.090\end{array}$ & $\begin{array}{c}19.4 \\
0\end{array}$ & $\begin{array}{l}45 \\
55\end{array}$ \\
\hline 6 & $\begin{array}{l}1.243 \\
1.243\end{array}$ & $\begin{array}{l}0.31 \\
0.36\end{array}$ & $\begin{array}{l}1.150 \\
1.139\end{array}$ & $\begin{array}{c}16.0 \\
0\end{array}$ & $\begin{array}{l}75 \\
25\end{array}$ & 3.55 & $\begin{array}{l}1.244 \\
1.244\end{array}$ & $\begin{array}{l}0.38 \\
0.49\end{array}$ & $\begin{array}{l}1.144 \\
1.102\end{array}$ & $\begin{array}{c}20.3 \\
0\end{array}$ & $\begin{array}{l}75 \\
25\end{array}$ & 2.5 & $\begin{array}{l}1.243 \\
1.243\end{array}$ & $\begin{array}{l}0.44 \\
0.55\end{array}$ & $\begin{array}{l}1.126 \\
1.117\end{array}$ & $\begin{array}{c}22.9 \\
0\end{array}$ & $\begin{array}{l}59 \\
41\end{array}$ \\
\hline 4.2 & $\begin{array}{l}1.237 \\
1.237\end{array}$ & $\begin{array}{l}0.38 \\
0.52\end{array}$ & $\begin{array}{l}1.168 \\
1.176\end{array}$ & $\begin{array}{c}18.8 \\
0\end{array}$ & $\begin{array}{l}82 \\
18\end{array}$ & 2.5 & $\begin{array}{l}1.240 \\
1.240\end{array}$ & $\begin{array}{l}0.40 \\
0.37\end{array}$ & $\begin{array}{l}1.143 \\
1.029\end{array}$ & $\begin{array}{c}21.9 \\
0\end{array}$ & $\begin{array}{l}90 \\
10\end{array}$ & 2.0 & $\begin{array}{l}1.247 \\
1.247\end{array}$ & $\begin{array}{l}0.42 \\
0.42\end{array}$ & $\begin{array}{l}1.126 \\
1.133\end{array}$ & $\begin{array}{c}25.0 \\
0\end{array}$ & $\begin{array}{l}83 \\
17\end{array}$ \\
\hline 3.5 & $\begin{array}{l}1.243 \\
1.243\end{array}$ & $\begin{array}{l}0.37 \\
0.45\end{array}$ & $\begin{array}{l}1.170 \\
1.165\end{array}$ & $\begin{array}{c}19.4 \\
0\end{array}$ & $\begin{array}{l}87 \\
13\end{array}$ & 1.55 & $\begin{array}{l}1.240 \\
1.240\end{array}$ & $\begin{array}{l}0.37 \\
0.38\end{array}$ & $\begin{array}{l}1.151 \\
0.98\end{array}$ & $\begin{array}{c}23.1 \\
0\end{array}$ & $\begin{array}{r}93 \\
7\end{array}$ & 1.7 & $\begin{array}{l}1.245 \\
1.245\end{array}$ & $\begin{array}{l}0.41 \\
0.58\end{array}$ & $\begin{array}{l}1.128 \\
1.164\end{array}$ & $\begin{array}{c}26.0 \\
0\end{array}$ & $\begin{array}{l}83 \\
17\end{array}$ \\
\hline 2.35 & $\begin{array}{l}1.243 \\
1.243\end{array}$ & $\begin{array}{l}0.39 \\
0.49\end{array}$ & $\begin{array}{l}1.176 \\
1.265\end{array}$ & $\begin{array}{c}20.1 \\
0\end{array}$ & $\begin{array}{r}92 \\
8\end{array}$ & & & & & & & 1.5 & $\begin{array}{l}1.226 \\
1.226\end{array}$ & $\begin{array}{l}0.43 \\
0.58\end{array}$ & $\begin{array}{l}1.115 \\
1.123\end{array}$ & $\begin{array}{c}26.1 \\
0\end{array}$ & $\begin{array}{l}86 \\
14\end{array}$ \\
\hline 1.5 & $\begin{array}{l}1.243 \\
1.243\end{array}$ & $\begin{array}{l}0.37 \\
0.44\end{array}$ & $\begin{array}{l}1.170 \\
1.231\end{array}$ & $\begin{array}{c}20.6 \\
0\end{array}$ & $\begin{array}{r}93 \\
7\end{array}$ & & & & & & & 1.4 & $\begin{array}{l}1.243 \\
1.243\end{array}$ & $\begin{array}{l}0.35 \\
0.53\end{array}$ & $\begin{array}{l}1.122 \\
1.130\end{array}$ & $\begin{array}{c}27.1 \\
0\end{array}$ & $\begin{array}{l}88 \\
12\end{array}$ \\
\hline
\end{tabular}

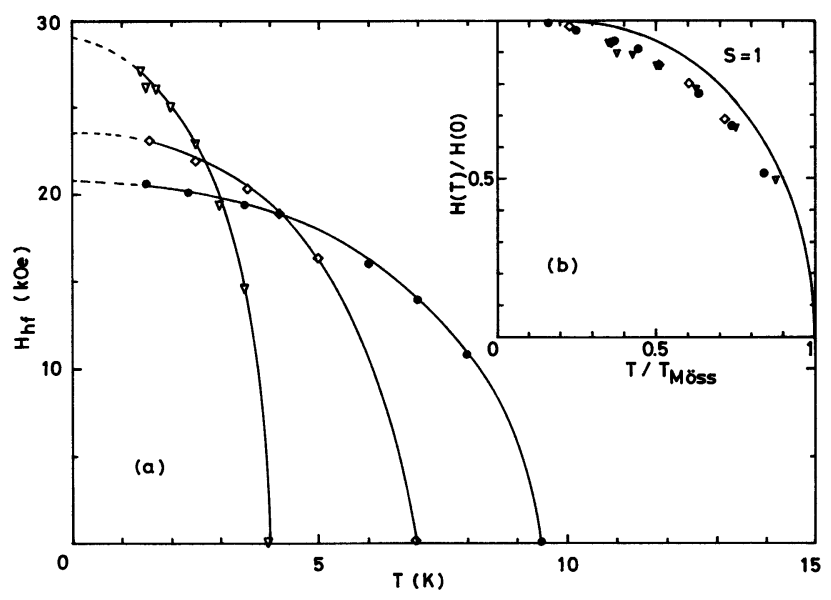

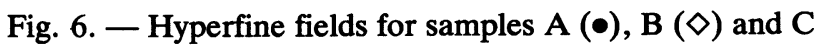
(V). 6a : Hyperfine fields versus temperature (full lines are only guides to the eye). $6 \mathrm{~b}$ : Reduced hyperfine field against reduced temperature and comparison with Brillouin behaviour for $S=1$.

to the first peak $\left(H_{\mathrm{hf}}=0\right)$ decreases when the temperature is lowered whereas the population corresponding to the second peak increases. For sample A, the field distribution does not exhibit two resolved peaks. When $T$ is lowered, it progressively drops to almost zero for low hyperfine field values. This difference in behaviour is illustrated in figure 7 , which shows, for the same reduced temperature $\left(T / T_{\text {Möss }}=0.6\right)$, the field distribution for the three samples. For $x=0.55$, which is the concentration corresponding to an antiferromagnetic phase at low temperatures, the magnetic ordering at $T / T_{\text {Möss }}=$ 0.6 involves most of iron ions in the crystal. Let us note that a recent neutron diffraction study (Wong $e t$ al. [15]) clearly showed, for a sample of the same iron concentration as that of sample $A$, that an antiferromagnetic structure does exist below $7.5 \mathrm{~K}$, but that short-range order coexists with long-range magnetic order. In this case, the magnetic component in the Mössbauer spectra would then essentially corresponds to well ordered antiferromagnetic domains.

4.2.3 Magnetic relaxation. - Relaxation models have been used for analysing Mössbauer spectra of spin-glasses. They assume a unique relaxation frequency depending on temperature. Recently Litterst et al. for $\mathrm{Eu}_{1-x} \mathrm{Gd}_{x} \mathrm{~S}$ [4], Sanchez et al. for $\mathrm{Eu}_{x} \mathrm{La}_{1-x} \mathrm{~S}$ [20] interpreted their data using such models. In the case of dilute alloys $\mathrm{Au} 6 \% \mathrm{Fe}$ and $\mathrm{Rh} 5 \% \mathrm{Fe}$, Meyer et al. [21, 22] invoked both relaxation broadening and static inhomogeneous broadening and finally conclude in both systems that the broadening was chiefly of a static inhomogeneous type for all spectra recorded at $T<T_{\text {Möss. }}$.

In the present case a relaxation model does not seem to be appropriate because both foregoing fitting procedures clearly show, at least for samples $B$ and $C$, that two distinct spin populations are present : the spins which are strongly coupled appear to be static or slowly relaxing, the other spins, uncoupled or weakly interacting, appear to be fastly 


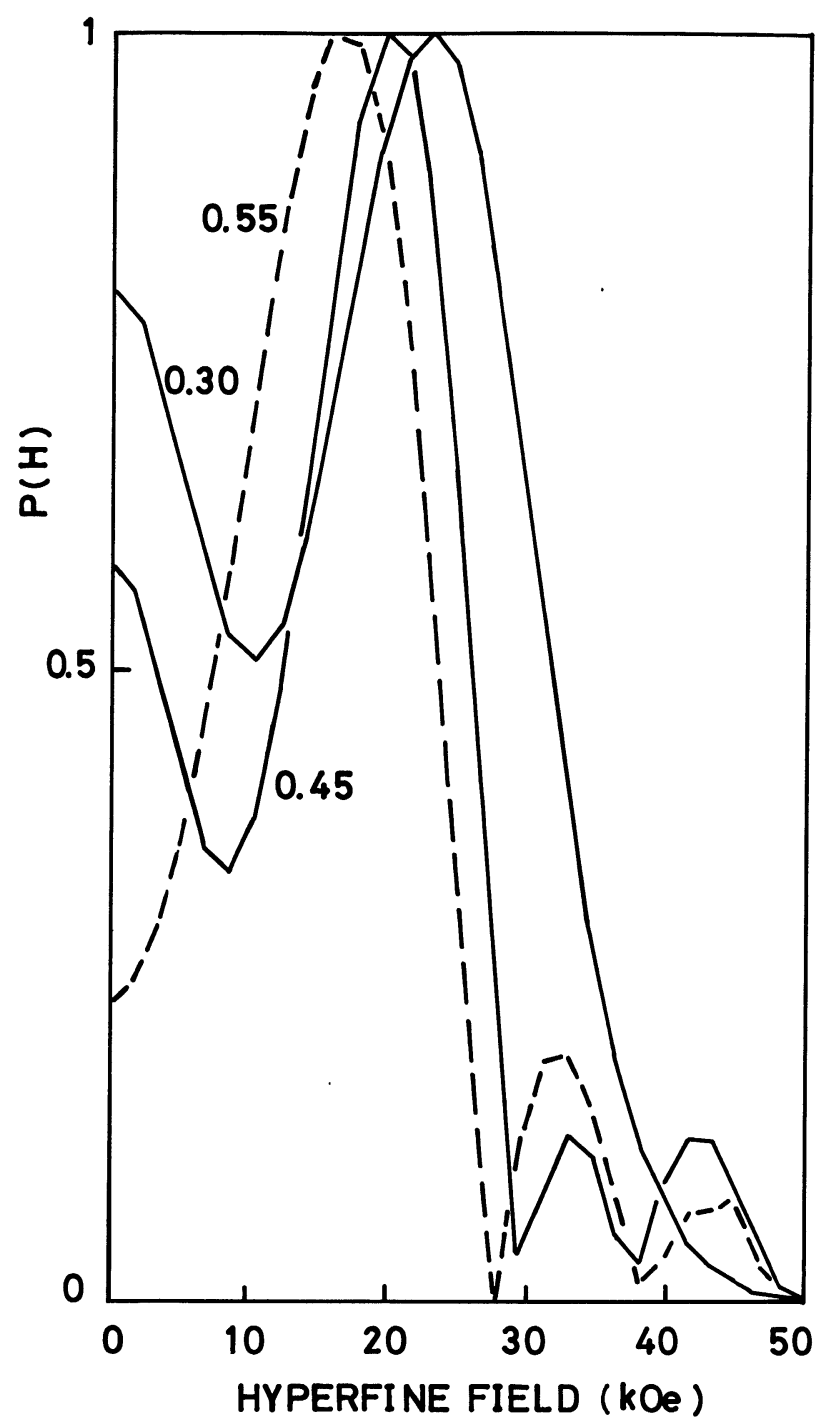

Fig. 7. - Hyperfine field distribution for samples A, B and $\mathrm{C}$ at the same reduced temperature $\left(T / T_{\text {Möss }}=0.6\right)$.

relaxing. Nevertheless we performed a relaxation analysis for the spin glass compounds $\mathrm{B}$ and $\mathrm{C}$ assuming a mean relaxation frequency $\bar{W}$. In the case of the $\mathrm{Fe}_{x} \mathrm{Mg}_{1-x} \mathrm{Cl}_{2}$ compounds which present a strong Ising character, an axial relaxation process may be considered, the hyperfine field being allowed to jump between two opposite directions (parallel to the $c$ axis) with equal probabilities (Wickman et al. [23]).

From this analysis we found, for samples $\mathrm{B}$ and $\mathrm{C}$, that, near $T_{\text {Möss }}$, the mean frequency $\bar{W}$ seems to follow an Arrhenius law $\bar{W}=W_{0} \exp \left(-E_{\mathrm{a}} / k T\right)$. For sample B we found $W_{0} \simeq 5 \mathrm{MHz}$ and $E_{\mathrm{a}} / k \simeq$ $7.5 \mathrm{~K}$ and for sample $\mathrm{C}, W_{0} \simeq 12 \mathrm{MHz}$ and $E_{\mathrm{a}} / k \simeq$ $5 \mathrm{~K}$. It has to be noticed that these activation energies $E_{\mathrm{a}} / k$ are quite comparable, in both cases, to $T_{\text {Möss }}$. However these results have to be looked at with caution, for we believe that we also have an inhomogeneous magnetic system. We think that these measured $\bar{W}$ values reflect, to a high degree, the existence of a paramagnetic component. At very low temperatures $(T \simeq 1.5 \mathrm{~K})$ when this component is weak, we found $\bar{W} \simeq 0.3 \mathrm{MHz}$, that is a value which is an order of magnitude smaller than the nuclear Larmor frequency $\nu_{\mathrm{L}}\left(\nu_{\mathrm{L}} \simeq 3 \mathrm{MHz}\right.$ in an applied field of $30 \mathrm{kOe}$ ). Thus at very low temperatures the Mössbauer spectrum can be considered as being essentially due to static magnetism at the Mössbauer time scale. But at higher temperatures, when the magnetic component is still visible, we cannot rule out for this component some relaxation broadening in addition to some broadening originating from a hyperfine field distribution which is quite probably present, at all temperatures, in such compounds with cationic disorder.

\section{Discussion.}

The two outstanding points which have now to be discussed are the following :

i) $T_{\text {Möss }}$ is higher than $T_{\mathrm{f}}$

ii) an apparently paramagnetic component exists in addition to a magnetic component over a wide temperature range.

5.1 $T_{\text {Möss }}$ IS HIGHER THAN $T_{\mathrm{f} .}-$ For samples B and $\mathrm{C}$, the temperature $T_{\text {Möss }}$, where a magnetic hyperfine field appears, is about twice the $T_{\mathrm{f}}$ value obtained from the d.c. susceptibility measurements. Different $T_{\text {Möss }}$ and $T_{\mathrm{f}}$ have been already observed in the case of insulating spin glasses $[4,19,24]$ as well as in metallic spin glasses [21] and are generally associated with dynamical effects. In the case of $\mathrm{Eu}_{0.3} \mathrm{La}_{0.7} \mathrm{~S}$ Sanchez et al. [19] did find such a high difference between $T_{\text {Möss }}$ and $T_{\mathrm{f}}$ as we do in $\mathrm{Fe}_{x} \mathrm{Mg}_{1-x} \mathrm{Cl}_{2}$.

In the present case of the $\mathrm{Fe}_{x} \mathrm{Mg}_{1-x} \mathrm{Cl}_{2}$ system at $x=0.45$ and $x=0.30, T_{\text {Möss }}$ approximately corresponds to the temperature which has been evidenced by susceptibility measurements $(T \simeq 7 \mathrm{~K}$ for $x=0.45$ and $T \simeq 5 \mathrm{~K}$ for $x=0.30$ ), when, a low temperature Curie-Weiss like behaviour is observed. Below this temperature and in an appreciable temperature range above $T_{f}$, the parallel susceptibility obeys a Curie-Weiss law with a constant $C$ larger than the single ion high temperature constant $C_{0}$ (Bertrand et al. [10]). These results have been interpreted by the formation of superparamagnetic clusters. The existence of these clusters, already mentioned, would be responsible for the magnetic Mössbauer subspectrum which indicates that the relaxation frequency of these clusters is low, inferior to or of the same order of magnitude as the nuclear Larmor frequency.

Considering that the ferromagnetic first neighbour intraplane interaction $\left(J_{1}\right)$ is strong and that the 
second neighbour intraplane interaction $\left(J_{2}\right)$ and the interplane interaction $\left(J_{1}^{\prime}\right)$ are antiferromagnetic and much smaller $\left(J_{2} / J_{1} \simeq J_{1}^{\prime} / J_{1} \simeq 0.1[24]\right)$ it is reasonable to assume that the first clusters created when the temperature is decreased are ferromagnetic clusters made up of first neighbour spins and that they take place at relatively high temperatures. On the other hand, the spin glass state which results from the frustrating antiferromagnetic interactions $J_{2}$ and $J_{1}^{\prime}$, will occur at temperatures clearly lower than $T_{\text {Möss. }}$.

\subsection{INTENSITY VARIATION WITH TEMPERATURE OF} THE TWO MÖSSBAUER SUBSPECTRA. - Below $T_{\text {Möss, lowering the temperature, we observe a }}$ decrease of the intensity of the paramagnetic subspectrum. For sample A which presents an antiferromagnetic phase at low temperatures this decrease is rapid and we have seen (Fig. 7) that at $T / T_{\text {Möss }}=0.6$ the paramagnetic contribution is very small. For $x=0.45$ and $x=0.30$ (concentrations which correspond to a spin glass behaviour) the paramagnetic component decreases more progressively. In the following we present two mechanisms which could explain this behaviour.

At first such a behaviour could be qualitatively accounted for by assuming the existence of relaxing spin clusters of different sizes, the relaxation time for each cluster depending on its size and on the temperature. The presence of a particular cluster size distribution could thus explain the coexistence of the two subspectra over a rather wide temperature range. However, if rapid magnetic fluctuations can wipe out the hyperfine field, they cannot influence the quadrupolar interaction. The model cannot thus give account of the different quadrupolar interactions which are observed for the two subspectra.

As was discussed in a preceding part, we consider that first clusters evidenced at $T_{\text {Möss }}$ are made up of first neighbour spins connected by the strong ferromagnetic interaction $J_{1}$. The analysis of the quadrupolar interaction has shown that these clusters (independently of their size) are slowly fluctuating and correspond to the magnetic component of the spectra. Consequently the paramagnetic component concerns only isolated spins or weakly interacting spins. When the temperature is lowered, these spins join progressively the existing clusters and a decrease of the paramagnetic component is observed for the benefit of the magnetic component. When approaching the spin glass state, the cluster size strongly increases and a cooperative behaviour of interacting clusters probably occurs. This model is consistent with the results recently reported (Bensamka et al. [26]) in the case of the compound with the smaller magnetic ion concentration $x=0.30$. In this work a rapid increase of the non-linear part $\mathcal{M}_{\mathrm{nl}}$ of the static magnetization is observed in the temperature range $2.5 \mathrm{~K}$ to $1.7 \mathrm{~K}$ and is interpreted in the framework of a phase transition.

For sample $\mathrm{C}$, the spectrum recorded at the lowest temperature $(T=1.4 \mathrm{~K})$ shows that a weak fraction of spins is still paramagnetic. For the same iron concentration, in the field cooled susceptibility experiments [26] performed at low temperatures with an appropriate cooling rate, we do not observe a «plateau " and the susceptibility continues to increase. This behaviour is interpreted by assuming the presence of a small number of isolated spins which exist in a random distribution of magnetic ions in the case of an insulating compound with shortrange interactions and a low magnetic ion concentration $(x=0.30)$.

\section{Summary and conclusion.}

The magnetic behaviour of diluted insulating $\mathrm{Fe}_{x} \mathrm{Mg}_{1-x} \mathrm{Cl}_{2}$ compounds have been studied by Mössbauer spectroscopy for three iron concentrations $x=0.55, x=0.45$ and $x=0.30$. Contrary to the case of pure $\mathrm{FeCl}_{2}$, magnetic order gives rise to a measurable hyperfine field at low temperatures and it has been found that the magnetic moments do not appreciably deviate from the $c$ axis. Our Mössbauer measurements, on these Ising-like compounds, show that local magnetic order appears at a temperature $T_{\text {Möss }}$ which is higher than the temperature corresponding to the maximum of the susceptibility curve (zero field cooled curve). We found that $T_{\text {Möss }}$ is close to the temperature where a deviation from the single ion high temperature Curie Weiss law occurs. Below $T_{\text {Möss }}$ and down to $1.4 \mathrm{~K}$, the Mössbauer spectra are made up of two subspectra : one paramagnetic contribution and one magnetic contribution. Just below $T_{\text {Möss }}$, the local magnetic order is characterised by the existence of clusters made up of $\mathrm{Fe}^{2+}$ first neighbours in the cationic planes coupled by ferromagnetic interactions. When the temperature is lowered the magnetic clusters grow at the expense of the population of the uncoupled spins. This clustering process may be considered as the prelude to the spin glass phase transition. 


\section{References}

[1] Maletta, H. and Crecelius, G., J. Physique Colloq. 37 (1976) C6-645.

[2] Maletta, H. and Convert, P., Phys. Rev. Lett. 42 (1979) 108.

[3] Bauermann, T., Abd-Elmeguid, M. M., SANChez, J. P., TAKabatake, T. and Micklitz, H., J. Phys. C : Solid State Phys. 16 (1983) 6435.

[4] Litterst, F. J., Friedt, J. M., ThOlenCe, J. L. and Holtzberg, F., J. Phys. C: Solid State Phys. 15 (1982) 1049.

[5] Fiorani, F., Thèse, Grenoble (1984).

[6] Manns, V., Brand, R. A., Keune, W. and MarX, R., Solid State Commun. 48 (1983) 811.

[7] Ito, A., Torikai, E., Yamauchi, H. and Syono, Y., J. Phys. C : Solid State Phys. 15 (1982) 2759.

[8] Sanchez, J. P., Friedt, J. M., Horne, R. and DuYneVeldt, A. I., J. Phys. C : Solid State Phys. 17 (1984) 127.

[9] Bertrand, D., Fert, A. R., Schmidt, M. C., Bensamka, F. and Legrand, S., J. Phys. $C$ : Solid State Phys. 15 (1982) L883.

[10] Bertrand, D., Bensamka, F., Fert, A. R., Gelard, J., Redoules, J. P. and Legrand, S., J. Phys. C : Solid State Phys. 17 (1984) 1725.

[11] Cragg, D. M. and Sherrington, D., Phys. Rev. Lett. 49 (1982) 1120.

[12] Roberts, S. A. and Bray, A. J., J. Phys. C : Solid State Phys. 15 (1982).

[13] Wong Po-Zen and Molnar, S. Von, Bull. Am. Phys. Soc. 28 (1983) 511.
[14] Wong Po-Zen, Molnar, S. Von and Dimon, P., Solid State Commun. 48 (1983) 573.

[15] Wong Po-Zen, Molnar, S. Von, Palstra, T. T. M., Mydosh, J. A., Yoshizawa, H., Shapiro, S. M. and Ito, A., Phys. Rev. Lett. 55 (1985) 2043.

[16] Nasser, J. A. and VARret, F., Solid State Commun. 13 (1973) 381.

[17] Ono, K., Ito, A. and Fujtta, T., J. Phys. Soc. Japan 19 (1964) 2119.

[18] Jehanno, G., Bensamka, F., Bertrand, D. and FERT, A. R., J. High Hyperfine Interaction 28 (1986) 573.

[19] Sanchez, J. P., Friedt, J. M., Westerholt, K. and BACH, H., Phys. Rev. B 33 (1986) 45144521.

[20] Meyer, C., Hartmann-Boutron, F., Gros, Y., J. Mol. Mag. Mat., 46 (1985) 254-266.

[21] Meyer, C., Hartmann-Boutron, F. and Gros, Y., J. Physique 47 (1986) 1395-1404.

[22] Wickman, H. H., Klein, M. P. and Shirley, D. A., Phys. Rev. 152 (1966) 345-357.

[23] Pappa, C., HammanN, J., Jehanno, G. and Jacobini, C., J. Phys. C : Solid State Phys. 18 (1985) 2817-2830.

[24] Birgeneau, R. J., Yelon, W. B., Cohen, E. and MAKovSKY, J., Phys. Rev. B 5 (1972) 26072615.

[25] Bensamka, F., Bertrand, D., Fert, A. R. and Redoules, J. P., J. Phys. C : Solid State Phys. 19 (1986) 4741-4748. 